\title{
Highly polymorphic di- and trinucleotide microsatellite markers for the grapevine yellows disease vector Hyalesthes obsoletus (Auchenorrhyncha: Cixiidae)
}

\author{
Miriam IMO ${ }^{1}$, Julia LÜNEBURG ${ }^{1}$, Thomas HANKELN ${ }^{2}$, Alfred SEITZ ${ }^{1 *}$ and Jes JOHANNESEN ${ }^{1}$ \\ ${ }^{1}$ Department of Ecology, Zoological Institute, University of Mainz, J.-J.-Becher-Weg 13, D-55128 Mainz, Germany; \\ e-mail:imo@uni-mainz.de \\ ${ }^{2}$ Institute of Molecular Genetics, University of Mainz, J.-J.-Becher-Weg 30a, D-55128 Mainz, Germany
}

Key words. Cixiidae, Hyalesthes obsoletus, Bois noir, microsatellite, PCR

\begin{abstract}
Seven polymorphic microsatellite loci were developed for the planthopper Hyalesthes obsoletus, vector of stolbur 16SrXII-A phytoplasma. The loci have di- or trinucleotide repeat motifs and are highly variable with 10 to 22 alleles per locus. Observed heterozygosity ranged from 0.278 to 0.950 for the 78 individuals genotyped. One locus is sex-linked. No linkage between loci was found. All loci amplified consistently among phylogeographic as well as host-plant related samples and proved highly informative for population genetic studies.
\end{abstract}

\section{INTRODUCTION}

Epidemiological cycles of vector-transmitted diseases are greatly influenced by the dispersal ability and the host specificity of the vector (Weintraub \& Beanland, 2006). The polyphagous planthopper Hyalesthes obsoletus is the main vector of stolbur 16SrXII-A phytoplasma, a pathogen of many Solanaceae crops and responsible for the economically important grapevine yellows disease Bois noir $(\mathrm{BN})$ in Europe. The epidemiology of $\mathrm{BN}$ is primarily determined by the abundance of the vector on field bindweed (Convolvulus arvensis) and stinging nettle (Urtica dioica) (Maixner et al., 1995). Phenological differences in the life cycle of the vector on these two plants (Maixner et al., 2009) and the presence of plant-specific stolbur strains (Langer \& Maixner, 2004) indicate host-races of vector and host-strains of the pathogen, and hence two epidemiological disease cycles. However, the ability to test for genetic host races of the vector and determine its dispersal ability has been hampered by the extremely little genetic polymorphism in the markers so far analysed (mtDNA, RAPD-DNA, allozymes) This lack of polymorphism is most likely due to founder effects resulting from recent range expansion into large parts of the current European distribution (Johannesen et al., 2008). In the present paper, the development of microsatellite genetic markers that facilitate the study of the evolution of host races in $\mathrm{H}$. obsoletus and the epidemiology of $H$. obsoletus-transmitted diseases are reported.

\section{MATERIAL AND METHODS}

Genomic DNA was purified (DNeasy Kit, Qiagen, Hilden, Germany) and sheared by nebulization. The size fraction between 1 and $2.5 \mathrm{~kb}$ was electro-eluted from a $1 \%$ agarose gel, end-repaired using Klenow enzyme and T4 DNA polymerase, blunt-end ligated into dephosphorylated, SmaI-digested pUC 18 plasmid vector and transformed into electro-competent $E$. coli DH10B cells (Amid et al., 2001). After blue-white selection, about 1000 white colonies were analyzed for the presence of microsatellite-containing inserts by colony filter hybridization.
Synthetic oligonucleotides representing a mixture of the various di- and trinucleotide motifs (30 mers) were radio-labelled using T4 polynuclotide kinase and gamma-P32-ATP (Hartmann Analytic, Braunschweig, Germany). Hybridization was performed at $40^{\circ} \mathrm{C}$ in $6 \times \mathrm{SSC} / 1 \%$ sodium-dodecylsulfate overnight, followed by washes at $50^{\circ} \mathrm{C}$ in $2 \times \mathrm{SSC}$ and $1 \times \mathrm{SSC}(1 \times \mathrm{SSC}$ contains $0.015 \mathrm{M}$ trisodium citrate and $0.15 \mathrm{M}$ sodium chloride). Autoradiography was performed using Kodak X-Omat films (Sigma-Aldrich, St. Louis, USA).

Plasmid DNA from positive clones was isolated in a 96-well format (Qiagen) and sequenced by the Sanger method using DyeTerminator chemistry (Applied Biosystems, Weiterstadt, Germany). Sequencing reactions were separated on an ABI3730 sequencer by a commercial service (StarSeq, Mainz, Germany). Bioinformatic identification of microsatellite stretches was performed with the program SciRoKo (Kofler et al., 2007).

Eighteen loci with repeat motifs were isolated (GenBank Accession no. HM046814-HM046831). For fluorescent labelling, the cost-efficient one-tube single-reaction nested PCR method described by Schuelke (2000) was used first. An 18-bp M13 primer was added to the 5 ' end of each forward primer and a fluorescent-labelled M13 primer was added to the PCR. PCR amplification was performed using PuReTaq Ready-To-Go PCR beads (GE Healthcare, Munich, Germany) following PCR conditions described in Schuelke (2000). Cycling conditions were: $5 \mathrm{~min}$ at $94^{\circ} \mathrm{C}, 30$ cycles of $30 \mathrm{~s}$ at $94^{\circ} \mathrm{C}, 45 \mathrm{~s}$ at $55 / 59 / 60 / 64^{\circ} \mathrm{C}$, $45 \mathrm{~s}$ at $72^{\circ} \mathrm{C}$, followed by 8 cycles of $30 \mathrm{~s}$ at $94^{\circ} \mathrm{C}, 45 \mathrm{~s}$ at $53^{\circ} \mathrm{C}$, $45 \mathrm{~s}$ at $72^{\circ} \mathrm{C}$, with a final extension of $15 \mathrm{~min}$ at $72^{\circ} \mathrm{C}$. Samples were scored on an ABI3130 sequencer using $11.7 \mu \mathrm{l}$ HiDi formamide, $0.3 \mu \mathrm{L}$ ROX 500 standard (Applied Biosystems), and 1 $\mu 1$ of the PCR product. Loci were genotyped using GeneMapper 4.0 software (Applied Biosystems).

Loci that produced consistent results were amplified in two QIAGEN Multiplex PCR reactions with four and three fluorescent labelled primers, respectively (mix 1: B82, F56, F84, and $\mathrm{H} 120$, annealing temperature $60^{\circ} \mathrm{C}$; mix 2: E96, G85, and C147, annealing temperature $62.5^{\circ} \mathrm{C}$ ). For the multiplex PCR, a PCR volume of $10 \mu \mathrm{l}(8.5 \mu \mathrm{l}$ mastermix and $1.5 \mu \mathrm{l}$ DNA of $c .50 \mathrm{ng}$

\footnotetext{
* Deceased.
} 
TABLE 1. Characteristics and summary statistics for microsatellite loci for Hyalesthes obsoletus based on 78 individuals from four populations sampled in Germany (D-U [U. dioica], $\mathrm{N}=20$, and $\mathrm{D}-\mathrm{C}[$ C. arvensis $], \mathrm{N}=20$ ), Italy (I), $\mathrm{N}=18$, and Israel (IL), $\mathrm{N}=20$.

\begin{tabular}{|c|c|c|c|c|c|c|c|c|c|c|c|c|c|}
\hline \multirow{2}{*}{$\begin{array}{l}\text { Locus } \\
\text { GenBank } \\
\text { Accession } \\
\text { no. }\end{array}$} & \multirow[b]{2}{*}{ Repeat motif } & \multirow[b]{2}{*}{ Primer sequences $\left(5^{\prime}-3^{\prime}\right)$} & \multirow[b]{2}{*}{$\begin{array}{l}\mathrm{T}_{\mathrm{a}}{ }^{1} \\
\left({ }^{\circ} \mathrm{C}\right)\end{array}$} & \multirow{2}{*}{$\begin{array}{l}\text { No. of alleles } \\
\text { D-U/D-C/ } \\
\text { I/IL/total }\end{array}$} & \multirow{2}{*}{$\begin{array}{l}\text { Allele } \\
\text { size } \\
\text { range } \\
\text { (bp) }\end{array}$} & \multicolumn{2}{|c|}{$\mathrm{D}-\mathrm{U}$} & \multicolumn{2}{|c|}{$\mathrm{D}-\mathrm{C}$} & \multicolumn{2}{|c|}{ I } & \multicolumn{2}{|c|}{ IL } \\
\hline & & & & & & $H_{O}^{2}$ & $H_{E}$ & $H_{O}$ & $H_{E}$ & $H_{O}$ & $H_{E}$ & $H_{O}$ & $H_{E}$ \\
\hline $\begin{array}{l}\text { Hob B82 } \\
H M 046815\end{array}$ & $(\mathrm{CA})_{10}$ & $\begin{array}{l}\text { F: TGTAAGCACAAGAGACCTATCG } \\
\text { R: CTCTTCCCTTCGTCAACG }\end{array}$ & 59 & $7 / 11 / 10 / 14 / 17$ & $131-171$ & 0.650 & 0.754 & 0.650 & 0.826 & 0.778 & 0.843 & 0.800 & 0.905 \\
\hline $\begin{array}{l}\text { Hob C147 } \\
H M 046818\end{array}$ & $(\mathrm{CA})_{21}$ & $\begin{array}{l}\text { F: GGTGTTTTTCCTCTACTGTCTGAG } \\
\text { R: GGACATGGCTACGTTCAACA }\end{array}$ & 60 & $5 / 11 / 8 / 13 / 18$ & $141-205$ & 0.750 & 0.569 & 0.900 & 0.901 & 0.556 & 0.744 & $0.278^{*}$ & 0.941 \\
\hline $\begin{array}{l}\text { Hob E96 } \\
\text { HM046820 }\end{array}$ & $\begin{array}{l}(\mathrm{GA})_{15} \\
\text { (interrupted } \\
\text { by four T) }\end{array}$ & $\begin{array}{l}\text { F: CGGCGTAAATTTGGAGAGAA } \\
\text { R: ATCCCTCTTCCCCTTCTTCA }\end{array}$ & 64 & $4 / 10 / 8 / 16 / 22$ & $160-218$ & 0.550 & 0.671 & 0.647 & 0.775 & $0.529 *$ & 0.818 & $0.526^{*}$ & 0.895 \\
\hline $\begin{array}{l}\text { Hob F56 } \\
H M 046823\end{array}$ & $(\mathrm{CCA})_{12}$ & $\begin{array}{l}\text { F: AAGGCGCACGTTTCTACTGT } \\
\text { R: TCGAAAATCGCGTTATCAGTC }\end{array}$ & 60 & $8 / 9 / 5 / 13 / 14$ & $164-215$ & 0.700 & 0.681 & 0.650 & 0.812 & 0.500 & 0.692 & 0.950 & 0.873 \\
\hline $\begin{array}{l}\text { Hob F84 } \\
H M 046824\end{array}$ & $(\mathrm{CA})_{13}$ & $\begin{array}{l}\text { F: CCACCTTTTCCCCTTATGAA } \\
\text { R: GAGACTCCAGTTGCCACACA }\end{array}$ & 60 & $5 / 8 / 3 / 10 / 10$ & $237-260$ & 0.700 & 0.628 & 0.950 & 0.792 & 0.556 & 0.584 & 0.600 & 0.794 \\
\hline $\begin{array}{l}\text { Hob G85 } \\
H M 046828\end{array}$ & $(\mathrm{CA})_{10}$ & $\begin{array}{l}\text { F: AGCAAACACCTGCCTCTGAA } \\
\text { R: CCAAAATTAGCGAACCGAAC }\end{array}$ & 64 & $6 / 8 / 6 / 15 / 18$ & $236-272$ & $0.526^{*}$ & 0.771 & $0.400 *$ & 0.699 & $0.353 *$ & 0.533 & $0.650 *$ & 0.927 \\
\hline $\begin{array}{l}\text { Hob H120 } \\
\text { HM046830 }\end{array}$ & $(\mathrm{CA})_{3} \mathrm{TA}(\mathrm{CA})_{7}$ & $\begin{array}{l}\text { F: AACTCTCATGCGGACCAGAC } \\
\text { R: AAGGGGATGGGTAGAACGAC }\end{array}$ & 60 & $5 / 7 / 8 / 11 / 12$ & $239-267$ & 0.750 & 0.638 & 0.850 & 0.803 & 0.944 & 0.814 & 0.684 & 0.886 \\
\hline
\end{tabular}

${ }^{1} \mathrm{~T}_{\mathrm{a}}=$ annealing temperature. ${ }^{2}$ GENEPOP v. 4.0 .10 (Raymond \& Rousset, 1995) was used to calculate $H_{O}$ (observed heterozygosity), $H_{E}$ (expected heterozygosity). ${ }^{3}$ Sex-linked locus: The heterozygosity estimates for the German population were based only on females, whereas the sex of Italian and Israel populations were unknown. * denotes significant deviation from Hardy-Weinberg proportion $(P<0.05)$.

DNA per reaction) was used. The mastermix contained a final concentration of $1 \times$ QIAGEN Multiplex PCR Master Mix, which provides $3 \mathrm{mM} \mathrm{MgCl}$, and $0.2 \mu \mathrm{M}$ of each primer. Cycling conditions were: $30 \mathrm{~s}$ at $95^{\circ} \mathrm{C}, 30$ cycles of $30 \mathrm{~s}$ at $94^{\circ} \mathrm{C}, 90 \mathrm{~s}$ at $60 / 62.5^{\circ} \mathrm{C}, 90 \mathrm{~s}$ at $72^{\circ} \mathrm{C}$, followed by a final extension of 10 min at $72{ }^{\circ} \mathrm{C}$.

Genetic variability and amplification consistency was tested in two German, one Italian, and one Israel population. German populations (Bacharach) were syntopic and collected on Urtica dioica $(\mathrm{N}=20)$ and Convolvulus arvensis $(\mathrm{N}=20)$, respectively. Italian specimens $(\mathrm{N}=18)$ were collected near Rome on Urtica dioica. Israel specimens $(\mathrm{N}=20)$ were collected at several sites in the Central Golan Heights on Vitex agnus-castus. Genetic diversity indices, Hardy-Weinberg probabilities, and population differentiation were calculated with Genepop version 4.0.10 (Raymond \& Rousset, 1995). Genetic differentiation among populations, $F_{S T}$, was calculated using the method of Weir \& Cockerham (1984). Null alleles were tested using Micro-Checker version 2.2.3 (van Oosterhout et al., 2004) applying a Bonferroni correction for multiple comparisons (Rice, 1989).

\section{RESULTS}

Seven polymorphic microsatellite loci produced consistent results. These loci amplified consistently in all 78 specimens. 10-22 alleles per locus (mean 15.86) were recorded. The expected heterozygosity per locus ranged from 0.533 to 0.941 (Table 1). The loci B82, F56, F84, and H120 obeyed HardyWeinberg proportions in all populations. Locus C147 was sexlinked; males were always homozygous whereas females showed Hardy-Weinberg proportions. Locus E96 showed deviations from Hardy-Weinberg proportions in two populations and

TABLE 2. Pairwise $F_{S T}$ values based on 78 individuals of Hyalesthes obsoletus from four populations sampled in Germany (D-U [U. dioica], $\mathrm{N}=20$, and $\mathrm{D}-\mathrm{C}[C$. arvensis $], \mathrm{N}=20$ ), Italy (I), $\mathrm{N}=18$, and Israel (IL), $\mathrm{N}=20$. Overall $F_{S T}=0.12$. All $F_{S T}$ values were highly significant $(\mathrm{p}<0.0001)$.

\begin{tabular}{llll}
\hline & D-U & D-C & I \\
\hline D-C & 0.12 & & \\
I & 0.15 & 0.11 & \\
IL & 0.15 & 0.07 & 0.13
\end{tabular}

locus G85 showed significant but similar levels of homozygote excess in all populations.

The estimate of genetic differentiation among all populations was high for polymorphic microsatellite loci, $F_{S T}=0.12$. Pairwise $F_{S T}$ values are shown in Table 2 . All $F_{S T}$ values were highly significant $(P<0.0001)$.

Bayesian clustering analysis performed with Structure 2.1 (Pritchard et al., 2000) for individuals sampled on different host plants at the syntopic German site clustered all individuals, except one, according to the host plant on which they were collected (proportion of membership to bindweed $=0.915$, nettle $=$ 0.936).

\section{DISCUSSION}

The microsatellite loci reported here amplify consistently in $H$. obsoletus from diverse phylogeographic areas and hostplants. An overall departure from Hardy-Weinberg equilibrium was found for one locus, G85. Since there were no amplification failures at G85, and because the heterozygote deficit was constant across the four divergent populations, this indicates that a null-allele cannot alone explain the deficit (putative null allele frequencies $=0.11-0.16$ ). No linkage was found between any locus pair, therefore all loci can be considered as independent. The Israel population was the only one with an overall deviation from Hardy-Weinberg proportions. This might be caused by the Wahlund effect as no amplification failures were observed. The Wahlund effect is a reduction in expected heterozygosity of a population due to structuring into several subpopulations. Israel specimens where collected at several sites in the Central Golan Heights and might therefore not represent a single population.

The loci were able to detect population differentiation within and between geographic regions, as is indicated by high $F_{S T}$ values ranging from 0.07 to 0.15 . The Israel population is phylogenetically divergent from German and Italian populations, which belong to two related but separate post-glacial expanding lineages (Johannesen et al., 2008). In Germany, populations from different host plants showed significant genetic differentiation. The evidence provided here for geographic as well as hostplant related genetic variance show that the seven loci are highly informative for gaining insights into both host-race evolution in $H$. obsoletus and epidemiological cycles of $H$. obsoletus-transmitted diseases. 
ACKNOWLEDGEMENTS. This study was financially supported by the Rheinland-Pfalz Stiftung für Innovation (15202386261/861). We thank M. Maixner, G. Pasquini and R. Sharon for providing samples from Germany, Italy and Israel, respectively.

\section{REFERENCES}

Amid C., Bahr A., Mujica A., Sampson N., Bikar S.E., Winterpacht A., Zabel B., Hankeln T. \& Schmidt E.R. 2001: Comparative genomic sequencing reveals a strikingly similar architecture of a conserved syntenic region on human chromosome 11p15.3 (including gene ST5) and mouse chromosome 7. Cytogen. Cell Genet. 93: 284-290.

Johannesen J., Lux B., Michel K., Seitz A. \& Maixner M. 2008: Invasion biology and host-specificity of the grapevine yellows disease vector Hyalesthes obsoletus in Europe. Entomol. Exp. Appl. 126: 217-227.

Kofler R., Schlötterer C. \& Lelley T. 2007: SciRoKo: a new tool for whole genome microsatellite search and investigation. Bioinformatics 23: 1683-1685.

LANGER M. \& MAIXNER M. 2004: Molecular characterisation of grapevine yellows associated phytoplasmas of the stolburgroup based on RFLP-analysis of non-ribosomal DNA. Vitis 43: 191-199.

Maixner M., Ahrens U. \& Seemüller E. 1995: Detection of the German grapevine yellows (Vergilbungskrankheit) MLO in grapevine, alternative hosts and a vector by a specific PCR procedure. Eur. J. Plant Pathol. 101: 241-250.

Maixner M., Johannesen J. \& Seitz A. 2009: Aspects of the interaction of stolbur phytoplasma, vectors and host plants in the epidemic systems of Bois Noir. Progrès Agricole et Viticole, Hors Série - Extended abstracts, 16th Meeting of ICVG, Dijon, France, 31 August - 4 September, pp. 141-142.

Pritchard J.K., Stephens M. \& Donnelly P. 2000: Inference of population structure using multilocus genotype data. Genetics 155: 945-959.

RAYMOND M. \& Rousset F. 1995: GENEPOP (version 1.2): population genetics software for exact tests and ecumenicism. J. Hered. 86: 248-249.

Rice W.R. 1989: Analyzing tables of statistical tests. Evolution 43: $223-225$.

SchuelKe M. 2000: An economic method for the fluorescent labelling of PCR fragments. Nature Biotechnol. 18: 233-234.

van Oosterhout C.V., Hutchinson W.F., Wills D.P.M. \& SHIPLEY P. 2004: Micro-Checker: software for identifying and correcting genotying errors in microsatellite data. Mol. Ecol. 4: $535-538$.

Weintraub P.G. \& Beanland L. 2006: Insect vectors of phytoplasmas. Annu. Rev. Entomol. 51: 91-111.

Weir B.S. \& Cockerham C.C. 1984: Estimating F-Statistics for the analysis of population structure. Evolution 38: $1358-1370$.

Received June 2, 2010; revised and accepted July 28, 2010 